\title{
The Thunderstorm Forecasting System at the Kennedy Space Center
}

\author{
Chartes J. Nimuann ${ }^{1}$ \\ Spaceflight Meteorology Ciroup, ${ }^{2}$ NOA A, Miami, Fla.
}

(Manscript received 19 May 1971)

\begin{abstract}
One of the major problems concerning meteorologists at the Kennedy Space Center, Fla, involves the forecasting of thunderstorm activity and associated adverse weather phenomena. The purpose of the study is to outline some of the more successful diagnostic tools which have been developed to aid the forecaster. These involve a variety of statistical procedures including conditional probabilities, exposure-period probabilities, and systems of multiple-regression equations based on nonlinear predictors.
\end{abstract}

\section{Introduction and forecast requirements}

One of the major problems concerning meteorologists having forecast responsibility for the Cape Kennedy area of Florida is the prediction of afternoon convective thunderstorm activity and associated adverse weather parameters. In addition to the obvious effect of such weather on manned and unmanned spacecraft launches, thunderstorms and threats of thunderstorms interfere with normal outdoor support functions and may endanger workers and equipment during the main thunderstorm months, May through September. Since it is desirable to reduce these risks and work stoppages to a minimum, considerable effort has been expended to develop diagnostic tools to aid the forecaster. The results of most of these efforts have been informally published, or published in media not generally available to the meteorological community. Since some of these procedures may be adaptable elsewhere, this summary is presented.

The type of thunderstorm forecast issued at Cape Kennedy depends to a large degree on the forecast period itself. Long-range planning forecasts are essentially nonconditional and present only minor details on thunderstorm-associated weather parameters. Forecasts issued between 1 and 5 days prior to a mission ${ }^{3}$ are more conditional since the forecaster has knowledge of expected tropospheric flow patterns derived from routinely received facsimile products. Forecasts issued

\footnotetext{
${ }^{1}$ Present affiliation: National Hurricane Center, NOAA, Miami, Fla.

2 Through funds transferred from the NASA Office of Manned Space Flight, the Spaceflight Meteorology Group (SMG) provides the primary operational meteorological support for the NASA manned spaceflight programs. Military weather support to the Air Force Eastern Test Range programs at the Space Center complex is provided by Detachment 11, 6th Weather Wing, Air Weather Service. The thunderstorm forecasting system described herein is a joint effort of the SMG and the local AWS Detachment 11

${ }^{3}$ As used herein, the term mission implies any weather sensitive activity whether it be a major event such as the manned launch or a minor event such as routine maintenance on a launch tower.
}

on the day of a mission are still more conditional since an observed atmospheric sounding is available. Forecasts issued shortly before a mission (at which time a GO or NO-GO decision on the basis of weather might be made) must give mesoscale details based on an elaborate observational network as well as the meteorologist's short-range forecast.

\section{Thunderstorms over the Florida Peninsula}

Portions of peninsular Florida observe more seasonal thunderstorm activity than any other part of the United States and, as pointed out by Landsberg (1958), the area is one of the prime thunderstorm-genesis regions of the world. A unique combination of geographical and meteorological conditions contributes to this condition. There is a virtually inexhaustible supply of low-level moisture with attendant conditional instability. Furthermore, the land mass is large enough to allow vigorous afternoon convection with further lifting action supplied by sea-breeze convergence (Byers and Rodebush, 1958). On the synoptic scale, further enhancement or suppression of the diurnal convective cycle occurs in response to certain recognizable patterns.

As would be expected, there are marked temporal and spatial variations to the thunderstorm activity. Fig. 1 shows the relationship of Cape Kennedy to the rest of the peninsula insofar as the spatial maximum is concerned during the peak two-month period July and August. Although the isopleths (isoceraunics) on the figure are based on long-term averages for the stations concerned, the analysis should be considered subjective in data-sparse regions such as over and around Lake Okeechobee (west-northwest of PBI). The records show further that considering the May through September season as a whole, almost all of the activity is confined to the period 1000 to $2200 \mathrm{EST}$. For this reason, the term afternoon thunderstorm, as used in 


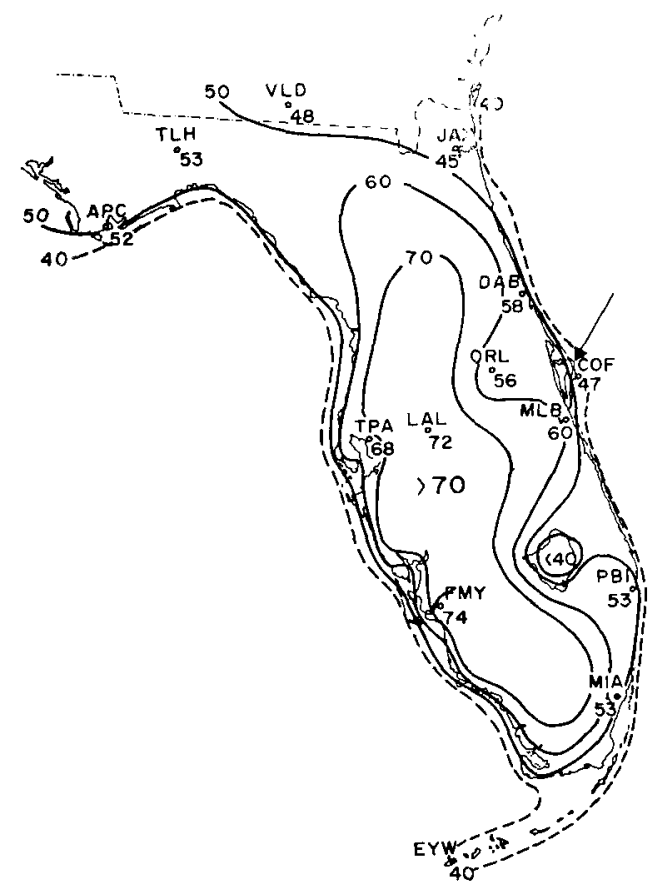

FIG. 1. Percent of days reporting thunderstorms in July and August. Arrow shows location of Kennedy Space Center.

this report, refers to thunderstorms beginning or ending between these hours.

Although Fig. 1 depicts a thunderstorm maximum over the western half of the peninsula, synoptic forecasting experience has shown that the position of the maximum on any given afternoon is not so well defined and is a function of the existing low-tropospheric wind field. In general, with a substantial easterly wind component, the maximum occurs further westward. Based on digitized radar data and 850 -mb winds, Frank $e t$ al. (1967) have documented this condition. The authors have shown further that light and variable winds tend to be associated with a double maximum, that is, one just inland from both coasts.

Using this and a priori reasoning leads to the conclusion that insofar as the Kennedy Space Center is concerned, a westerly low-level wind component is required to advect land-mass thunderstorms across the complex. Light and variable winds might result in thunderstorms building overhead. Thus, the summertime forecast problem at Cape Kennedy (as well as other sites in Florida) is primarily one of forecasting the low-tropospheric wind field, and to a lesser extent, the attendant synoptic-scale convergence-divergence pattern.

\section{Data source}

An essentially complete record of surface and upper air weather observations is available at Cape Kennedy dating back through 1957. In addition, surface and limited upper air data are available for the years 1951 and 1952. Tabulations of the beginning and ending times of all thunderstorm events ${ }^{4}$ as entered on the WBAN 10A forms were transferred to magnetic tape. Also residing on this tape (starting in 1957) are the 1200 GMT upper winds, temperatures, heights and relative humidities at $50-\mathrm{mb}$ increments from 1000 to $150 \mathrm{mb}$. Each of the studies referred to in this report. utilizes at least 13 years of record from this tape.

In an average year at Cape Kennedy, 94 individual thunderstorm events occur on 70 calendar days. In Falls et al. (1971), monthly frequency distributions of the number of thunderstorm events per day are presented. Falls discusses the parent probability distributions which fit these data and presents tables which point out that the conditional probability of a second thunderstorm event on any given day at the Space Center is always less than 0.50 . Thus, unless the forecaster has strong indications to the contrary, his best estimate is that another thunderstorm event will not occur on that day, once the initial event has ended.

\section{Empirical or conceptual probabilities?}

In meteorological practice the term probability is often ascribed to a set of data derived from relative frequencies. In the didactic sense, the term probability should be used only if 1 ) the relative frequencies are derived from an infinite number of observations, or 2) an underlying probability distribution is identified and fitted to a finite data sample.

The term "empirical" is often used to describe probabilities derived from relative frequencies. Mills (1955) discusses the concept and its counterpart "conceptual probabilities," the latter being known apart from experience. Whether or not one chooses to use conceptual or empirical probabilities depends to a large degree on the uses to which the data are to be put. The main advantage in identifying a parent distribution is that the data are smoothed and inferences about the dependent variable can be made outside the range of observation of the independent variable. One of the disadvantages is that the parent distribution may not be obvious or may be extremely complex. There is always the danger of selecting an imprecise distribution even though statistical tests, such as the well-known chi-square test, do not indicate rejection.

For day-to-day operational requirements, the author considers it advantageous to use empirical probabilities when a long period of record is available. Any one of several smoothing functions can be applied, resulting, within the range of observations, in a satisfactory estimate to the true probability. As used herein, the term "probability" refers to an estimate of the true probability as indicated by these smoothed empirical probabilities.

4 According to standard observational practice, a thunderstorm has ended $15 \mathrm{~min}$ after the observer last hears thunder. Thus, a day on which thunder is heard can have one or more thunderstorm events. 

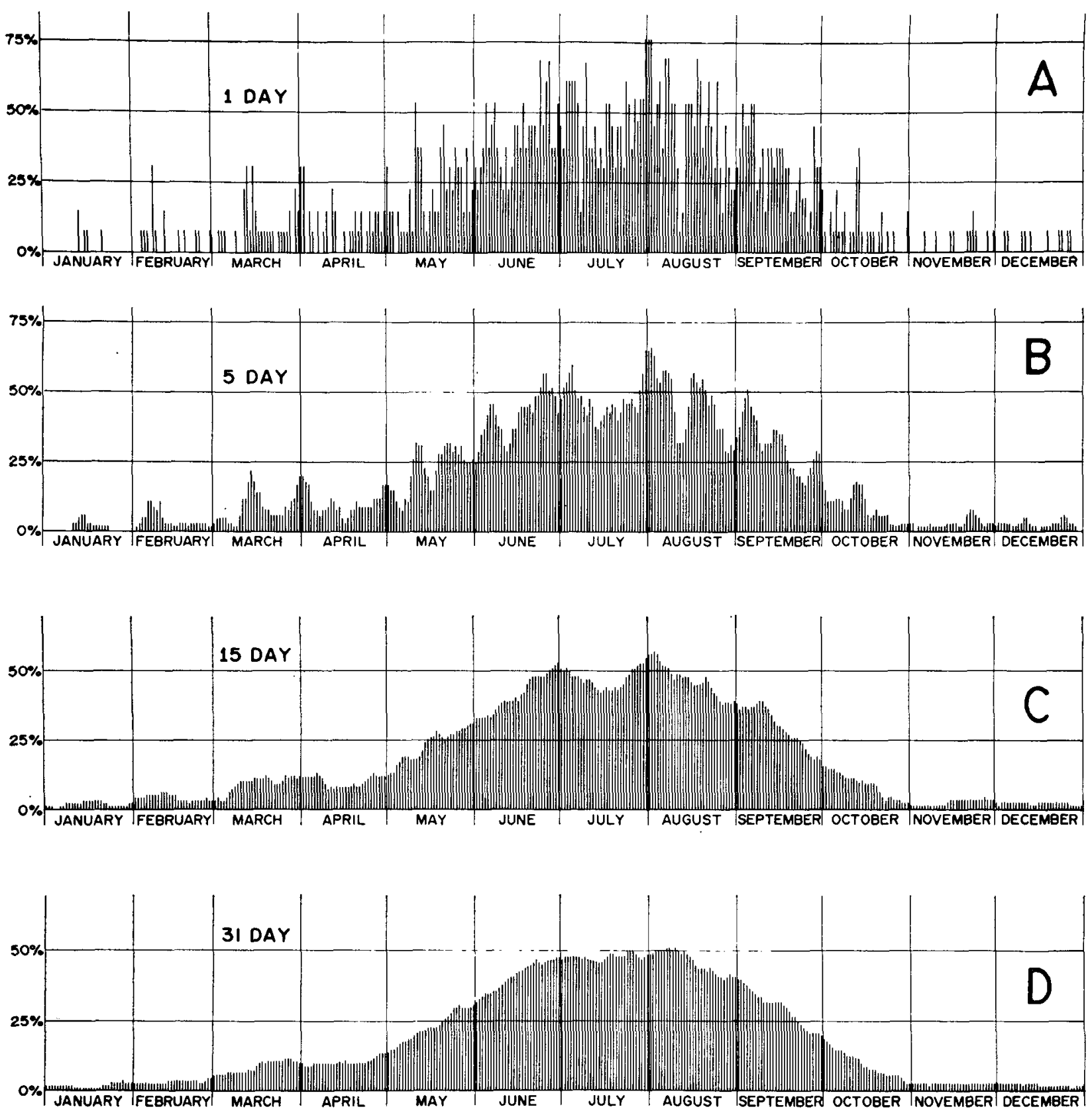

FIG. 2. Daily thunderstorm frequencies (top panel) smoothed over periods of 5,15 and 31 days.

\section{Forecast aids designed for long range planning}

\section{a. Smoothing of dependent data sample}

In the previous section, it was elected not to fit the observed data to a probability distribution function. Smoothing of the data sample was therefore required and a 15-day moving average was selected as a satisfactory smoothing function. The decision to use a 15day smoothing period was made after an analysis of computer-generated plots of the daily "thunderstorm- day"5 relative frequencies. The results of this smoothing are shown in Fig. 2. The 1-day values given on the chart are simply the numbers of thunderstorm days out of 13 possible years expressed on a percentage scale. The remaining panels of Fig. 2 show the smoothing over periods of 5,15 , and 31 days. The 5 -day plot still shows too much scatter and some presumably fictitious quasi-periodicities have been introduced.

${ }^{5}$ A thunderstorm day is defined as a day (based on local standard time) upon which thunder is recorded at least once. 
TABLE 1. Empirical probability of thunderstorms at specific hours on 1 August.

\begin{tabular}{cc}
\hline Time & $\begin{array}{c}\text { Empirical Probability } \\
\text { (percent) }\end{array}$ \\
\hline 1000 & 1 \\
1100 & 2 \\
1200 & 6 \\
1300 & 10 \\
1400 & 14 \\
1500 & 20 \\
1600 & 23 \\
1700 & 18 \\
1800 & 17 \\
\hline
\end{tabular}

Brooks and Carruthers (1953) caution about attaching any significance to such results. The 31-day plot seems to show excessive smoothing in that some of the real intra-seasonal variations are filtered out. The 15-day smoothing period does not show excessive scatter and is still short enough to preserve cyclical variations explainable by known atmospheric processes. The dip in probability observed in mid-July is real and shows up in response to runs of thunderstorm-free periods associated with the mid-tropospheric ridge line being positioned directly over central Florida at this time. Other known intra-seasonal processes shown by Fig. 2 (panel $\mathrm{C}$ ) are the sudden onset of prefrontal squallline type thunderstorms in early March and the increase in nocturnal (2200-1000 EST) thunderstorm contribution to the daily frequencies in early September. The 15-day smoothed relative frequencies were therefore accepted as providing satisfactory estimates of the unconditional thunderstorm probabilities on any given date.

\section{b. The concept of exposure period probabilities}

Planning forecasts of thunderstorm activity, as well as of other weather events expressible in the binomial yes or no mode, are always presented to the user in terms of exposure-period probabilities. The concept is discussed by Smith et al. (1967). To illustrate, consider Table 1 . These data, based only on hourly observations, suggest relatively low probabilities and are apt to be misinterpreted by the user. If a mission is weather sensitive for the entire hour, say from 1500 to 1600 , the records at Cape Kennedy show that the probability of at least one thunderstorm increases to $30 \%$. If it is sensitive (as many missions are) for the entire 8-hr period, 1000 to $1800 \mathrm{EST}$, then the unconditional empirical probability is $48 \%$. For the two-day period 1-2 August, the probability is $73 \%$, and for the week starting 1 August, it rises to $97 \%$. The probability of at least one thunderstorm during the period 1-10 August approaches 100\%.

Computer-generated tables and graphical aids have been made available to the forecaster to facilitate providing this type of information to users. In all cases, the 15-day moving average smoothing function, dis- cussed previously, was applied to the data. Fig. 3, extracted from Neumann (1968), illustrates one such chart. This diagram (and others in the set) are originally presented in a large fold-out format to insure legibility of the computer printout. They enable the forecaster to present the unconditional probabilities according to the precise needs of the user.

The exposure-period data also reside on magnetic tape and can be processed in a variety of ways to satisfy particular requirements. If, for example, a thunderstorm sensitive mission is scheduled for 1 August, a chart similar to that shown in Fig. 4 might be prepared.

If a mission is sensitive only to afternoon thunderstorms, is to commence on 1 August and last for a number of days, then a chart similar to Fig. 5 can easily be prepared. Two sets of data are retrievable from this figure. The top scale gives the chance of observing at least one afternoon thunderstorm over any period of up to 10 days starting on 1 August. The bottom scale gives the chances of observing runs of afternoon thunderstorm days from 1-10 days duration starting on 1 August.

\section{c. Conditional probabilities}

The cumulative nature of the data shown in Fig. 5 facilitates the computation of conditional probabilities. What, for example, is the conditional probability of another afternoon thunderstorm on 2 August, having observed one on 1 August? A simple conditional probability $\left(P_{\mathbf{c}}\right)$ can be stated (Lass, 1957$)$, i.e.,

$$
P_{c}=P_{B}(A)=P(A \cap B) / P(B), \quad P(B) \neq 0 ;
$$

that is to say, the probability of $A$ occurring under the condition that $B$ has already occurred is equal to the probability of the joint occurrence of $A$ and $B$ divided by the probability of $B$ alone. Substituting the proper data from Fig. 5 into (1) gives

$$
P_{c}=35.4 / 50.8=0.70 \text {. }
$$

This tells the forecaster that in the past, afternoon thunderstorms observed 1 August have occurred again on 2 August on $70 \%$ of the occasions. Similarly, it can be shown that they can be expected on at least a third consecutive day $53 \%$ of the time. Detailed information pertaining to conditional probabilities is contained in Neumann (1968). The data show that the particular type of conditional probability computed in (2) exceeds 50\% from 30 May through 22 August. Being aware of this enables the forecaster to make an intelligent decision, assuming he is otherwise uncertain about the forecast.

\section{d. Thunderstorm duration}

Neumann (1968) also presents information relative to the expected duration of thunderstorms at the 


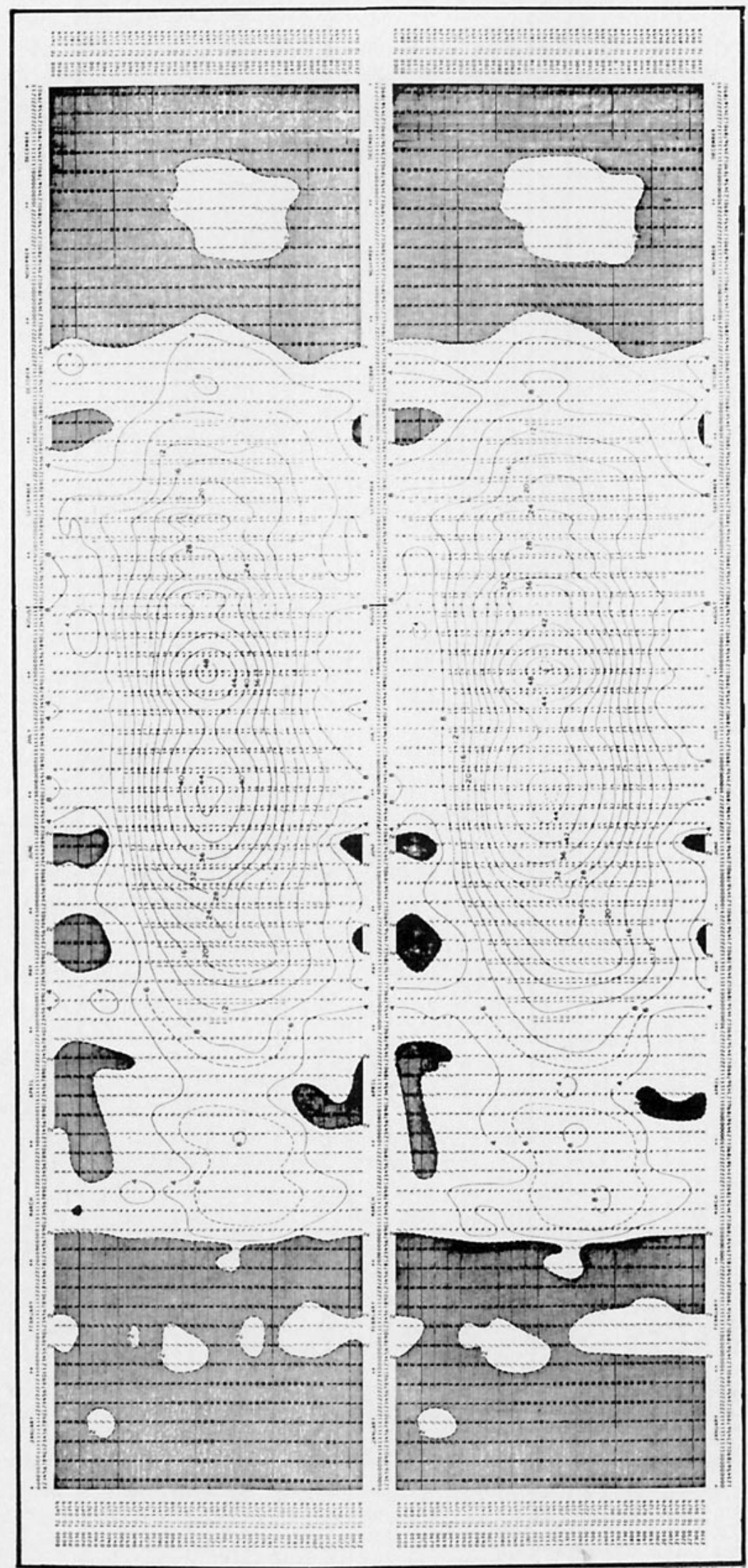

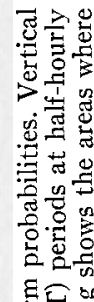

हैق

क्⿹

훙.

F⿻

옹

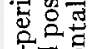

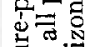

获

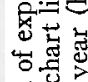

.

풍

究综

此

쓸

돕

엉응

옥:

$\overline{0}$

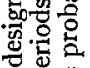

要类

柔尔

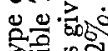

政.

要运

ธส สี

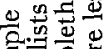

근

क्ष

要,

$\dot{m}$

o

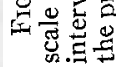




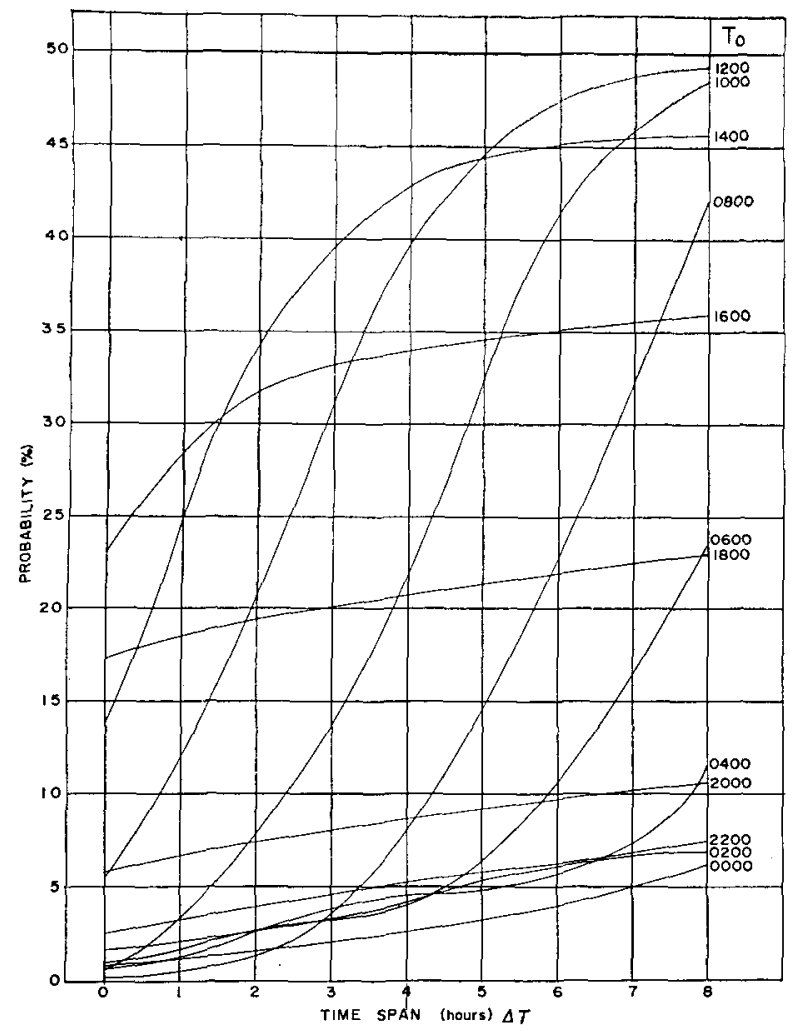

FIG. 4. Probability of at least one thunderstorm on 1 August between time, $T_{0}$ and $T_{0}+\Delta T$. Values of $T_{0}$ are based on Eastern Standard Time.

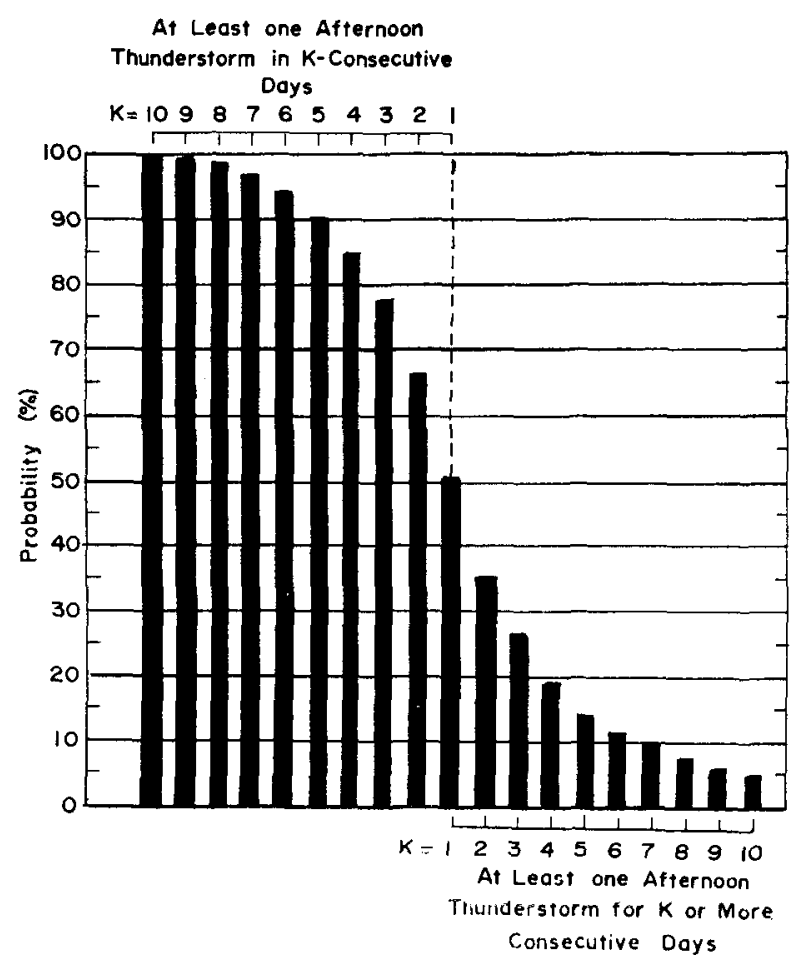

FIG. 5. Thunderstorm probabilities over extended time periods starting on 1 August,

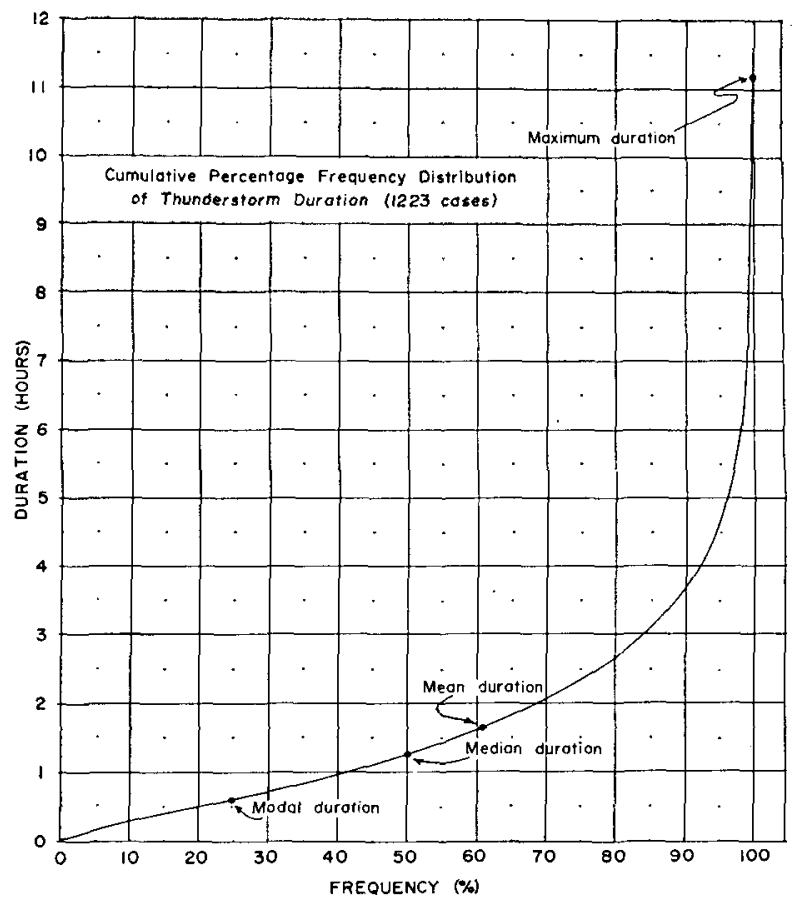

FIG. 6. Cumulative percentage frequency distribution of thunderstorm duration.

Kennedy Space Center. The cumulative percentage frequency curve shown on Fig. 6 is based on 1223 individual thunderstorm events. To offset the observational practice of ending a thunderstorm 15 min after thunder is last heard, this amount has been subtracted from each thunderstorm ending time. Once a thunderstorm starts, the forecaster can use the information contained in Fig. 6 to approximate ending times.

\section{The 1-5 day thunderstorm forecast}

The probabilities described in Section 5 are stated without regard to any particular weather situation and rapidly lose their utility when the forecast period decreases to 5 days or less. At that time, routinely received prognostic charts convey to the forecaster a knowledge of conditional parameters which bear on the thunderstorm forecast on the day of the mission. As pointed out in Section 2, the low-level flow pattern is one of the prime considerations.

Neumann (1970) presents a set of 31 empirically derived conditional probability tables, one for each of the 5-day periods between 1 May and 30 September. Fig. 7 shows the table to be used for the 5-day period 4-8 August. Given a 3000-ft wind forecast valid within this period, the forecaster can refer to the table for a consistent afternoon thunderstorm forecast. Details concerning the derivation of these charts and the reasons for selecting the $3000-\mathrm{ft}$ wind level are given in the above cited reference. A brief description of the charts themselves is given below. 


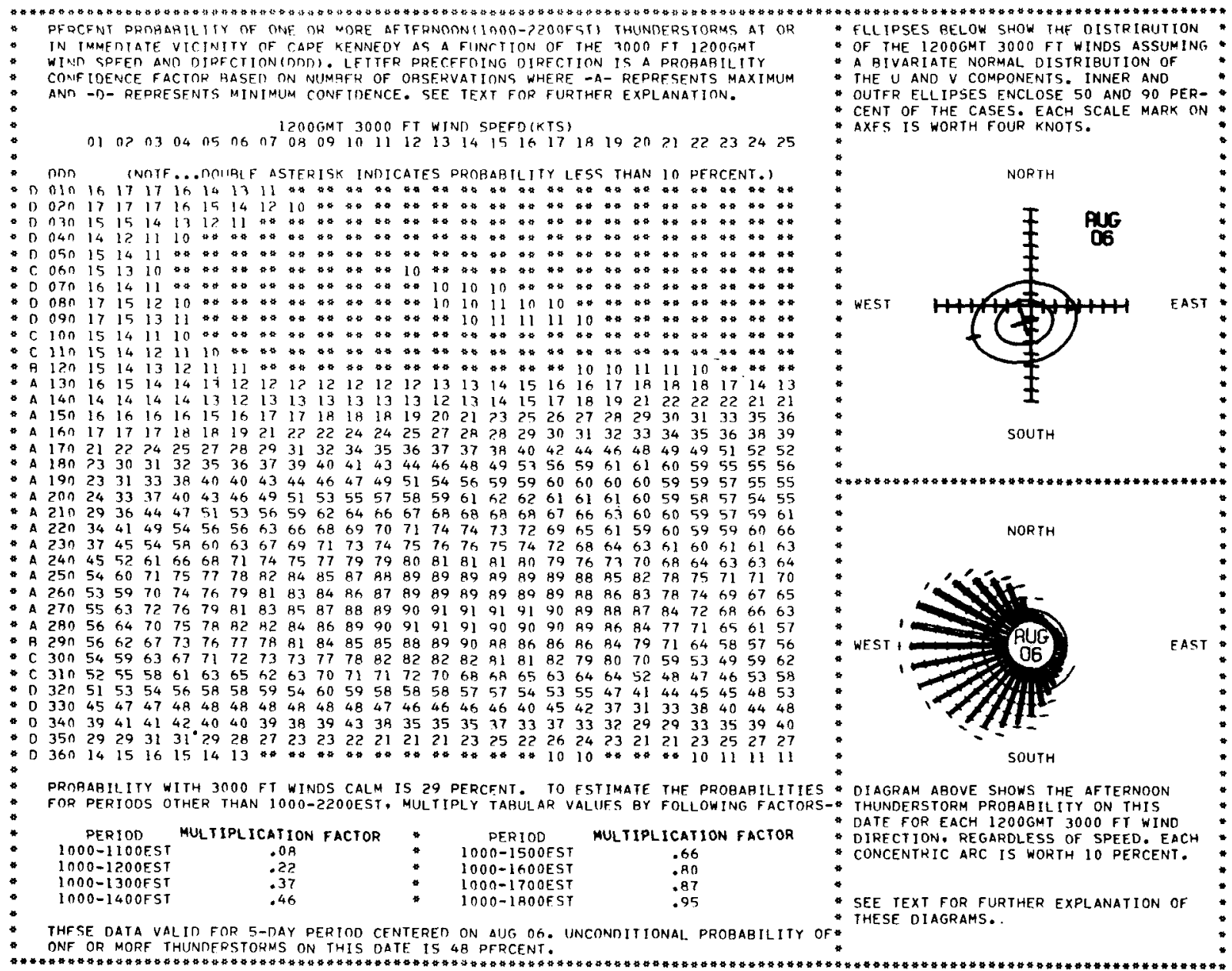

FIG. 7. Thunderstorm probabilities for 6 August as a function of the 1200 GMT $3000-\mathrm{ft}$ wind direction and speed.

The probabilities are given for each $3000-\mathrm{ft}$ wind direction for speeds of up to $25 \mathrm{kt}$. There were insuffcient data to derive empirically the probabilities for still higher speeds. This is a minor deficiency, for these speeds are observed only $3 \%$ of the time. Within the bounds of the table, the forecaster is further provided a relative confidence factor based on the number of observations used to compute the empirical probability data. The inset in the upper right-hand corner provides additional guidance along these lines. These ellipses have been drawn in the meteorological sense rather than the mathematical sense in order to enhance their operational utility. That is, they show the distribution of the tails of the wind vectors rather than the heads. The small elliptical area in the northern semicircle explains the assignment of a " $D$ " confidence factor to this portion of the table. Fig. 8 provides the forecaster with an overview of the 3000 -ft wind distribution throughout the year.

The inset in the lower right corner of Fig. 7 gives the empirical probability for each wind direction without regard to speed. The intent here is to give the forecaster a quick overview of the behavior pattern for this date, making him aware of the consequences of a missed wind forecast. A still broader overview is provided by Figs. 9 and 10.

Each of the Figs. 7-9 are 100\% computer-produced, thereby bypassing costly and time-consuming conventional drafting procedures. The format of the program output which produced Fig. 7 was designed for subsequent addition of the two insets, these being produced by an off-line $x, y$ plotter.

Returning to Fig. 7, the data appearing at the bottom of the probability tables enable the forecaster to assess the thunderstorm probabilities for periods shorter than 1000 to 2200 EST. These values were derived from the exposure-period probabilities given in Neumann (1968) and illustrated in Fig. 3.

Another diagnostic tool provided to the forecaster is shown in Fig. 11, which shows the resultant winds with all possible combinations of thunderstorm/nothunderstorm conditions. With afternoon thunder- 

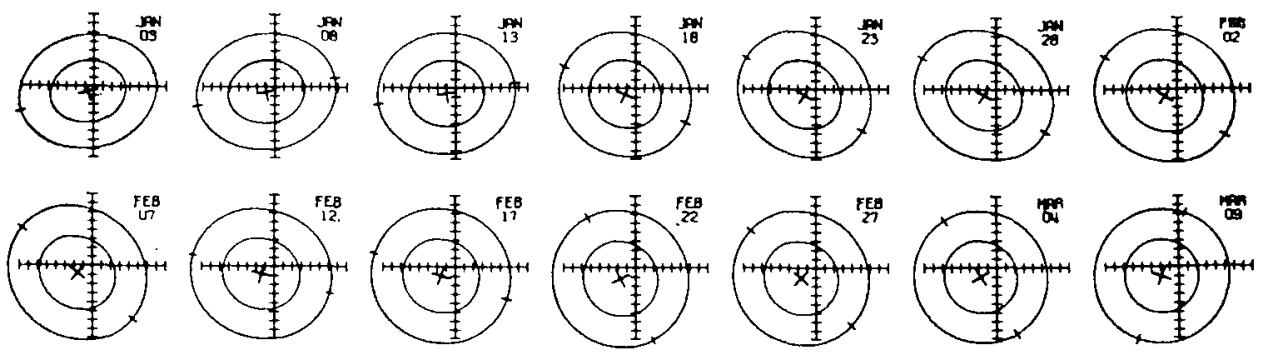

$\left(7^{1}\right.$
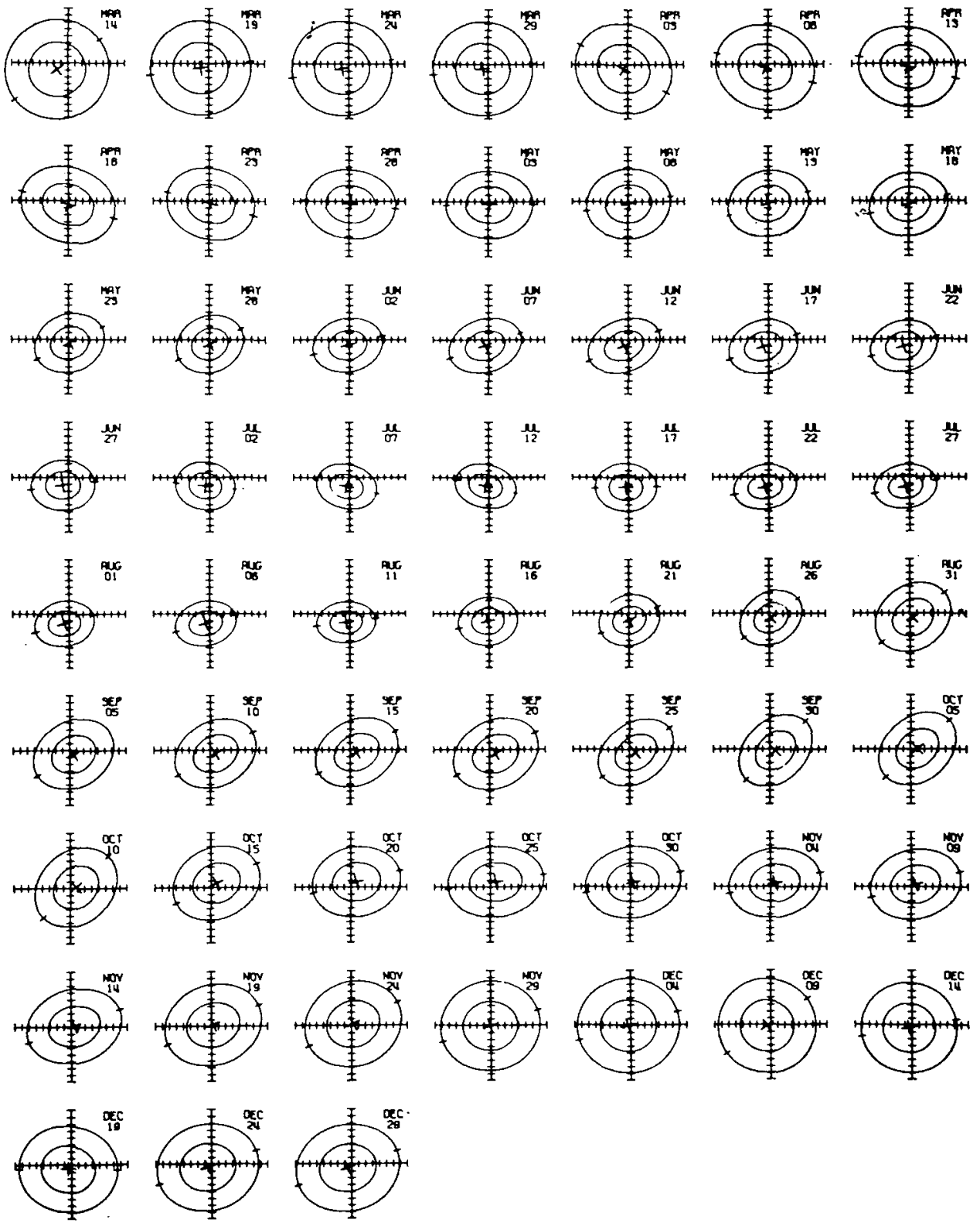

FIG. 8. Ninety and 50-percentile distributions of the 1200 GMT 3000-ft winds at the Kennedy Space Center assuming a bivariate normal distribution of the orthogonal wind components. Each set of ellipses is computed for the 25-day period centered on the specified date. The ellipses show the distribution of the wind from a particular direction. Each scale mark is $4 \mathrm{kt}$. The cross marks the centroid of the distribution. 

(송)
(1007)
$(\sqrt{1+13})$
(18)

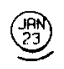
(1981)
(192)
⿶8)
(12)
(19)
(12)
(i)
(망
(ल98)

(iiv)

(9)

(4)

$(29)$

(⿶)

(18⿲二丨匕口

(19.9

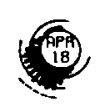
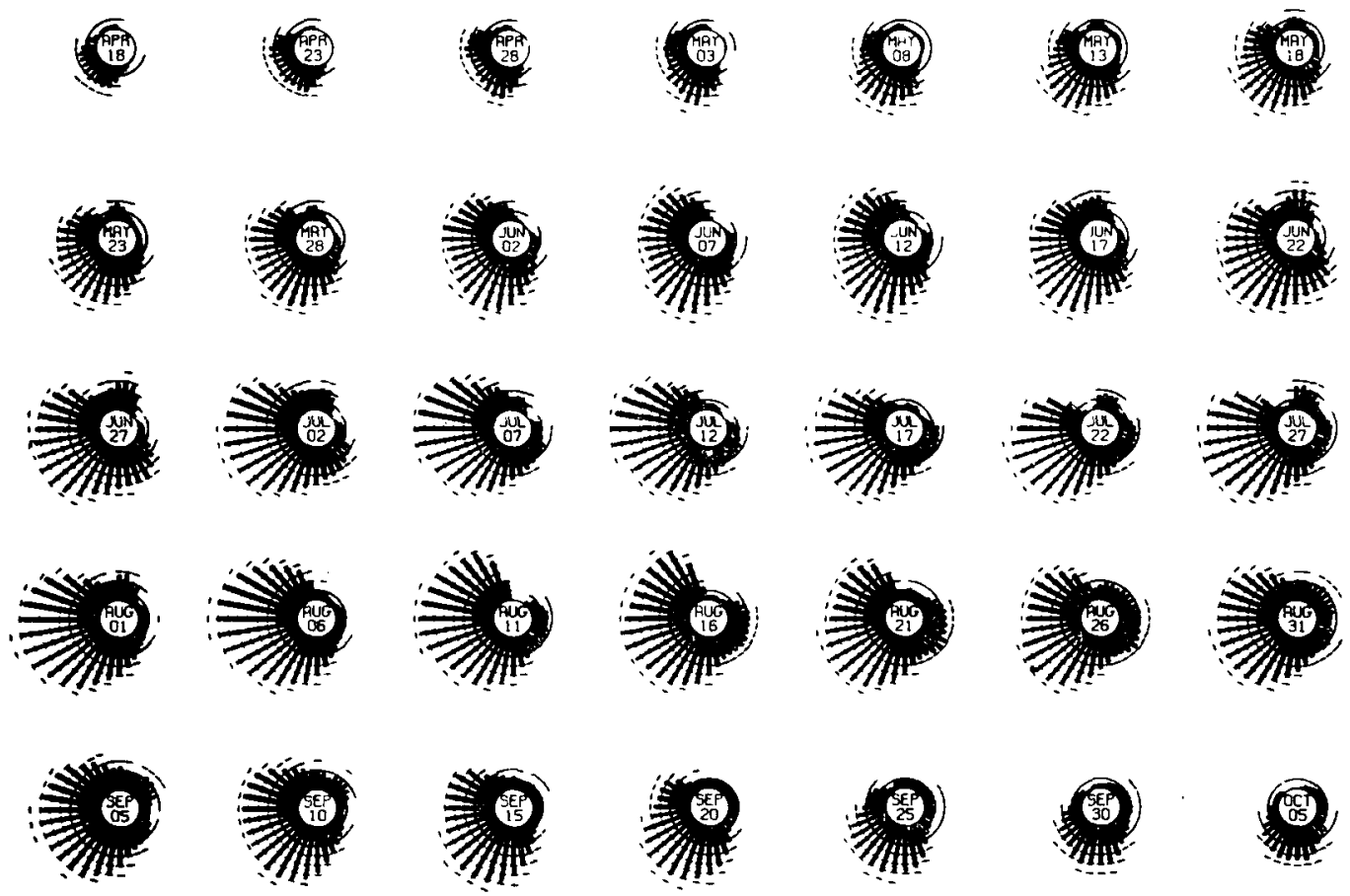

(10)

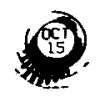

(ख)
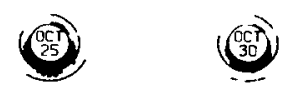

(vov)

(109)

(Iiv)

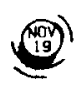

(저)

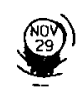

(ब4)

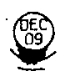

(14)

(190)

(저)

(29)

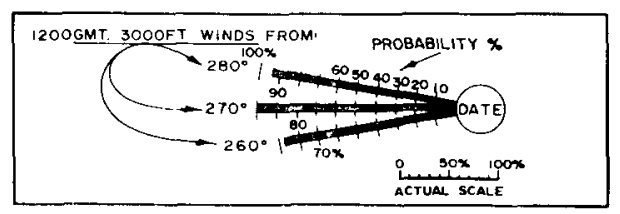

FIG. 9. Probability of afternoon (1000-2200 EST) thunderstorms on specified dates as a function of the $1200 \mathrm{GMT} 3000-\mathrm{ft}$ wind direction. 


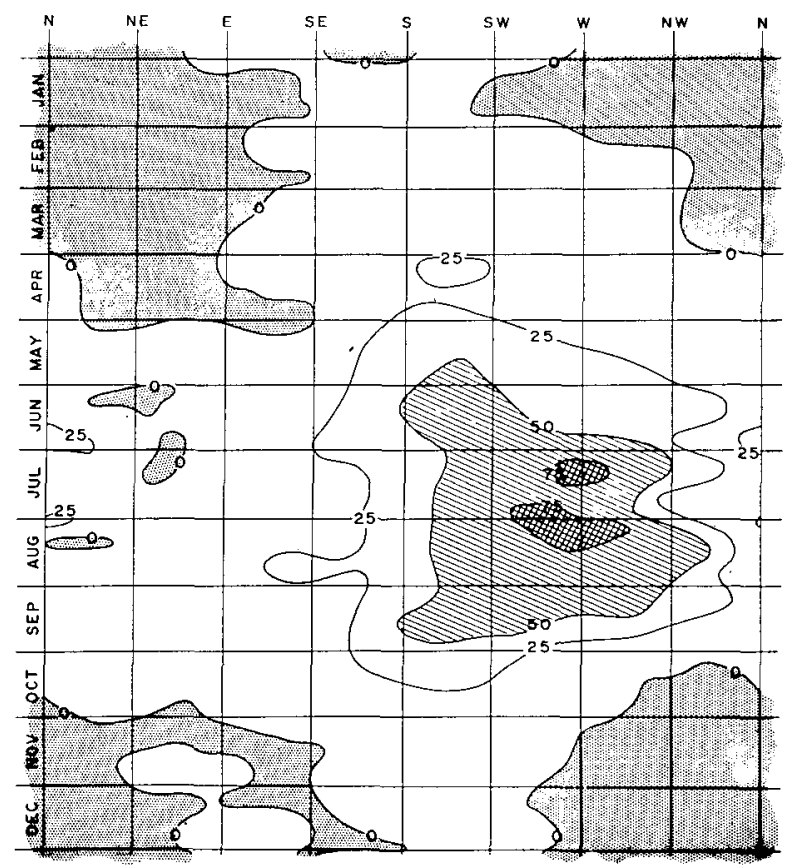

FIG. 10. Probability of afternoon thunderstorms (1000-2200 EST) on any given date as a function of the 1200 GMT $3000-\mathrm{ft}$ wind direction only. The dot pattern shows areas where, after smoothing, thunderstorms did not occur during the period of record. Cross-hatching shows areas where, after smoothing, afternoon thunderstorms occurred over $75 \%$ of the time.

storms, the resultant is seen to shift well southwestward, whereas, with only morning thunderstorms, the resultant shifts east-northeastward, perpendicular to the coastline.

\section{The short range $6-12 \mathrm{hr}$ forecast}

In the previous section, it was pointed out that the forecast $3000-\mathrm{ft}$ wind speed and direction could be used conditionally to arrive at a logical thunderstorm probability forecast for prognostic periods of from $1-5$ days. For still shorter ranges, the forecaster becomes aware of other parameters which also bear on the probability forecast. Most of these parameters are derived from the latest atmospheric sounding and, as will be shown, consist of the mid-tropospheric flow pattern, the synoptic-scale convergence and divergence pattern (as evidenced by midlevel moisture), and in some months the $850-500 \mathrm{mb}$ (Showalter) stability index. To assist the forecaster in assessing the importance of these parameters, a multiple-regression technique has been devised (Neumann, 1971). The program is stored in the same computer which reduces the Cape Kennedy sounding to a transmittable format, and thus can be run even before the forecaster sees the sounding. It is transmitted to NASA and Air Force interests around the Space Center along with the sounding itself. The format of the program output is shown in Fig. 12.

\section{a. Nonlinear regression}

One deficiency often noted in multiple regression techniques is that they assume each of the independent variables is a linear function of the dependent variables. From previous studies, it was known that some of the predictors (notably wind and moisture) were not linearly related to thunderstorm occurrence. For this reason, it was decided to incorporate nonlinearity in the

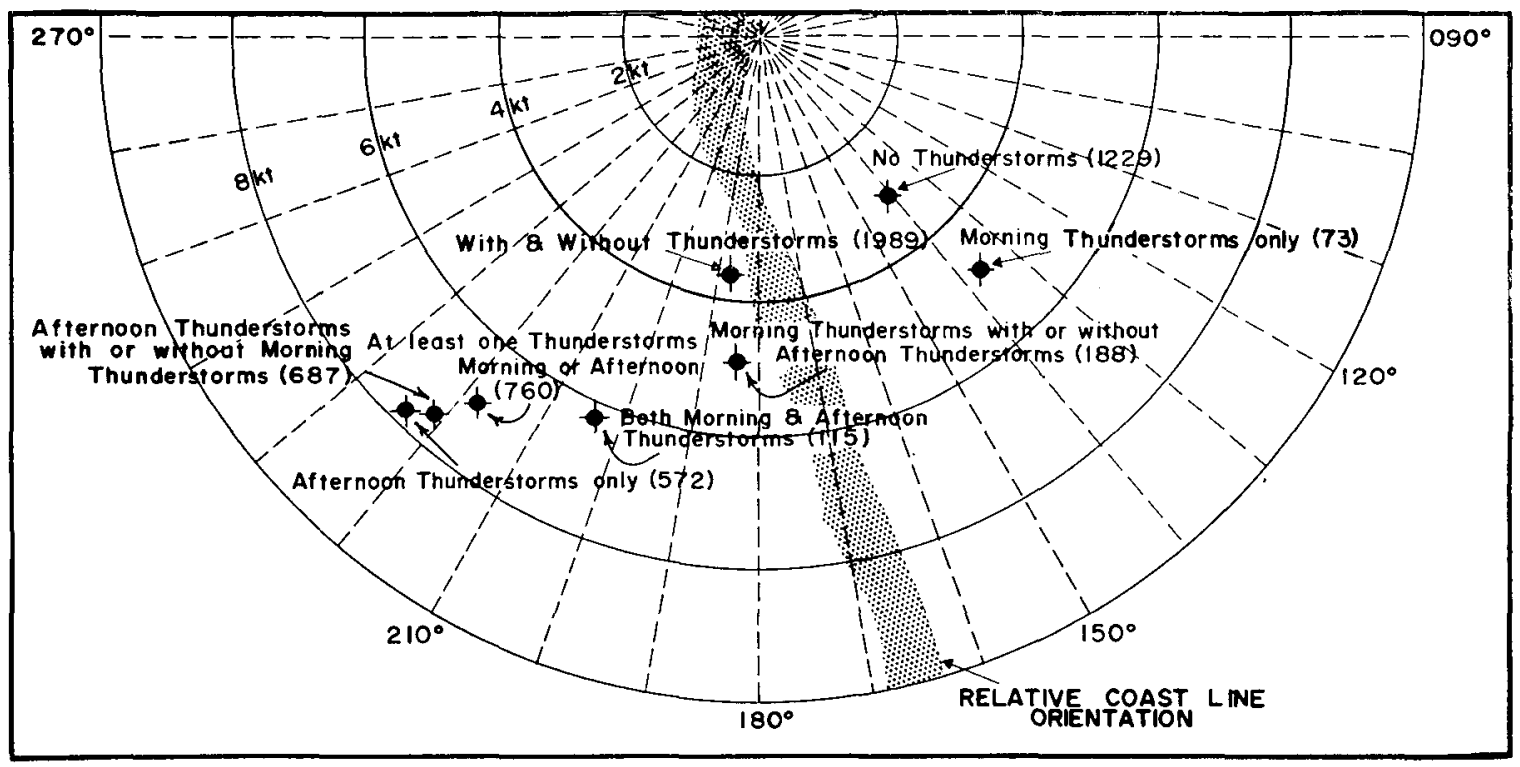

FIG. 11. Resultant 1200 GMT 3000-ft winds during the May through September thunderstorm season with various combinations of thunderstorm and no-thunderstorm days. Shading shows the relative location of the Florida eastern coast. The number of cases is given in parentheses. The location of each wind is the direction from which the resultant wind blows. 
prediction equations. The importance of nonlinearity was ascertained by screening against functions of the dependent variables in addition to the variables themselves. The general form of the regression equation used, where $P$ is probability and $X_{i}$ refers to a particular variable, is

$$
\begin{aligned}
P=C_{1}+C_{2} f\left(X_{1}\right)+C_{3} f\left(X_{2}\right)+C_{4}\left(X_{3}\right) & \cdots \\
& +C_{N+1} f\left(X_{N}\right) .
\end{aligned}
$$

The computer program used to solve for the constants $C_{1}$ through $C_{N+1}$ was modeled after the method described in Mills (1955) and involves the formulation of a covariance matrix. This is a standard technique and need not be outlined here.

In (3), if $f(X)$ is taken as the predictor itself (as is done in the above cited reference), then $f(X)=X$. If it is taken as a second-order polynomial, then

$$
f(X)=D_{1}+D_{2} X+D_{3} X^{2},
$$

while if it is taken as a third-order polynomial

$$
f(X)=E_{1}+E_{2} X+E_{3} X^{2}+E_{4} X^{3} .
$$

If the third-order polynomial represents a surface, then

$$
\begin{array}{r}
f(X)=f(U, V)=F_{1}+F_{2} U+F_{3} V+F_{4} U V+F_{5} U^{2} \\
+F_{6} V^{2}+F_{7} U^{3}+F_{8} U^{2} V+F_{9} U V^{2}+F_{10} V^{3} .
\end{array}
$$

In (4), (5) and (6), $D, E$ and $F$ are constants.

The concept of probability was introduced into the computations by assigning binomial values to $P$ such that if a thunderstorm did occur, $P$ was assigned a value of 1.0 , whereas if a thunderstorm did not occur, $P$ was assigned the value 0.0 . A separate set of prediction equations was formulated for each month. Therefore, if the unconditional probability of a thunderstorm for the month of June is 0.38 , then

$$
\frac{1}{N} \sum_{i=1}^{N} P_{i}=0.38
$$

where $P_{i}$ is the binomial probability assignment for a particular day and $N$ the number of days.

Initially, 250 predictors, each derived from the 1200 GMT sounding at $50-\mathrm{mb}$ intervals, were correlated against the binomial probability assignment. Climatology was introduced by including the day number as a predictor. The number of significant predictors was eventually narrowed from 250 down to 9. These were the orthogonal wind components at both 850 and 500 $\mathrm{mb}$, the relative humidity in the layer $800-600 \mathrm{mb}$, the Showalter stability index, the 900 -mb temperature, the $1000-850 \mathrm{mb}$ thickness, and the day number. Additional computer runs were then made with the predictor functions as derived from (4) and (5) as independent variables. Only if the functions gave significantly better correlations than the predictors themselves were the former selected for further analysis.

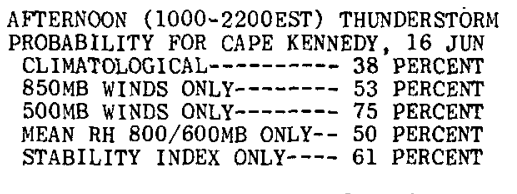

COMBINED PROBABILITY IS 87 PERCENT.

IF AN AFTERNOON THUNDERSTORM OCCURS, THE EST IMATED START ING TIME IS 1240EST PLUS OR MINUS $11 / 2$ HOURS.

FIG. 12. Sample output of multiple regression program with input data of $850-\mathrm{mb}$ wind $\left(180^{\circ}\right.$ at $\left.10 \mathrm{kt}\right), 500-\mathrm{mb}$ wind $\left(220^{\circ}\right.$ at $18 \mathrm{kt}$ ), mean $800-600 \mathrm{mb}$ relative humidity $(60 \%)$, and stability index of zero.

The axiom stated in Mills (1955) "unnecessary complications . . . are to be rigorously avoided" was followed in this regard.

One final refinement involved combining the orthogonal wind components at a given millibar level into a single function given by (6). Fitting a set of data to (6) is quite complex since 10 normal equations must be formulated to solve for the 10 unknown constants. The 10 equations are derived in Neumann and Hope (1971) and need not be repeated here. The amount of calculations involved render the fitting of a large set of data to (6) completely impractical without the aid of a digital computer.

\section{b. The prediction equations}

The terms selected for retention in the prediction equation varied slightly from month to month. However, in the interest of uniformity, all the terms were retained. The primary reduction in variance was contributed by the $850-\mathrm{mb}$ wind in all months. Of secondary significance was the $500-\mathrm{mb}$ wind followed by the mean relative humidity. Even though both of the wind functions are quite highly correlated with thunderstorm probability, they are also highly inter-correlated. The correlation coefficient between the two wind functions at 850 and $500 \mathrm{mb}$, for example, is 0.52 in June and 0.64 in August. Thus, including both levels in the prediction equations does not lower the multiple correlation coefficient as much as one might hope for. The Showalter stability index was quite significant as a predictor in May and June but contributed only slightly in the other months. Finally, the day number (climatology) contributed only slightly in all the months. All other terms were excluded since they did not contribute enough reduction in variance to warrant retention.

The prediction equation for the month of June was found to be

$$
\begin{aligned}
& P=-0.55562+0.61025 f\left(\bar{X}_{1}\right)+0.48518 f\left(\bar{X}_{2}\right) \\
& +0.36460 f\left(X_{3}\right)+0.35416 f\left(X_{4}\right)+0.63915 f\left(X_{6}\right),
\end{aligned}
$$

where $P$ is the probability $(0 \leqslant P \leqslant 1), \bar{X}_{1}$ the $850-\mathrm{mb}$ wind, $\bar{X}_{2}$ the $500-\mathrm{mb}$ wind, $X_{3}$ the mean relative humidity (percent) in the layer $800-600 \mathrm{mb}, X_{4}$ the 
stability index $\left({ }^{\circ} \mathrm{C}\right)$, and $X_{5}$ the day number (152 to 181 for June). The variance ratio $F$ realized from (7) is 40 . This value is clearly statistically significant at the $1 \%$ level using $F$ test criteria with the loss of the six degrees of freedom. In (7), the indicated functions are as follows:

$$
\begin{gathered}
f\left(\bar{X}_{1}\right)=f(s, t)=0.3327+0.2172 s / 10+0.2163 t / 10 \\
+0.3762 s t / 10^{3}-0.6836 s^{2} / 10^{3}+0.2579 t^{2} / 10^{3} \\
+0.1179 s^{3} / 10^{5}+0.1438 s^{2} t / 10^{5}-0.3374 s t^{2} / 10^{4} \\
-0.2200 t^{3} / 10^{4}
\end{gathered}
$$

where $s$ and $t$ are the orthogonal wind components in knots at $850 \mathrm{mb}$;

$$
\begin{gathered}
f\left(\bar{X}_{2}\right)=f(u, v)=0.2928+0.2638 u / 10+0.1023 v / 10 \\
+0.3207 u v / 10^{3}+0.7055 u^{2} / 10^{4}+0.1576 v^{2} / 10^{3} \\
-0.3090 u u^{3} / 10^{4}-0.1422 u^{2} v / 10^{4}+0.5589 u v^{2} / 10^{5} \\
-0.9225 v^{3} / 10^{5},
\end{gathered}
$$

where $u$ and $v$ are the orthogonal wind components in knots at $500 \mathrm{mb}$; and

$$
\begin{gathered}
f\left(X_{3}\right)=0.1350-0.1999 X_{3} / 10-0.8151 X_{3}{ }^{2} / 10^{3} \\
-0.6343 X_{3}^{3} / 10^{5}, \\
f\left(X_{4}\right)=0.6102-0.8067 X_{4} / 10+0.2404 X_{4}{ }^{2} / 10^{2}, \\
f\left(X_{5}\right)=-0.1323+0.1071 X_{5} / 10^{2}+0.1209 X_{5}{ }^{2} / 10^{4} .
\end{gathered}
$$

Graphical representation of (8)-(12) is given in Figs. 13-15. These latter figures and the graphical solution for the other months as well are made available to the forecaster so that a rapid assessment of the significant parameters can be made. The outer ellipse on Figs. 13 and 14 represent bounds to (8) and (9). Such bounding is required since, having expressed the probability by regression techniques rather than fitting to a probability distribution, nothing can be inferred outside the range of observations of the wind components. Without bounding, unrealistic values of $P$ might be produced by (8) and (9) with some unusual wind observation. Ezekiel (1941) points out the pitfalls of such practices. The bounding function to (8) is given by an equation

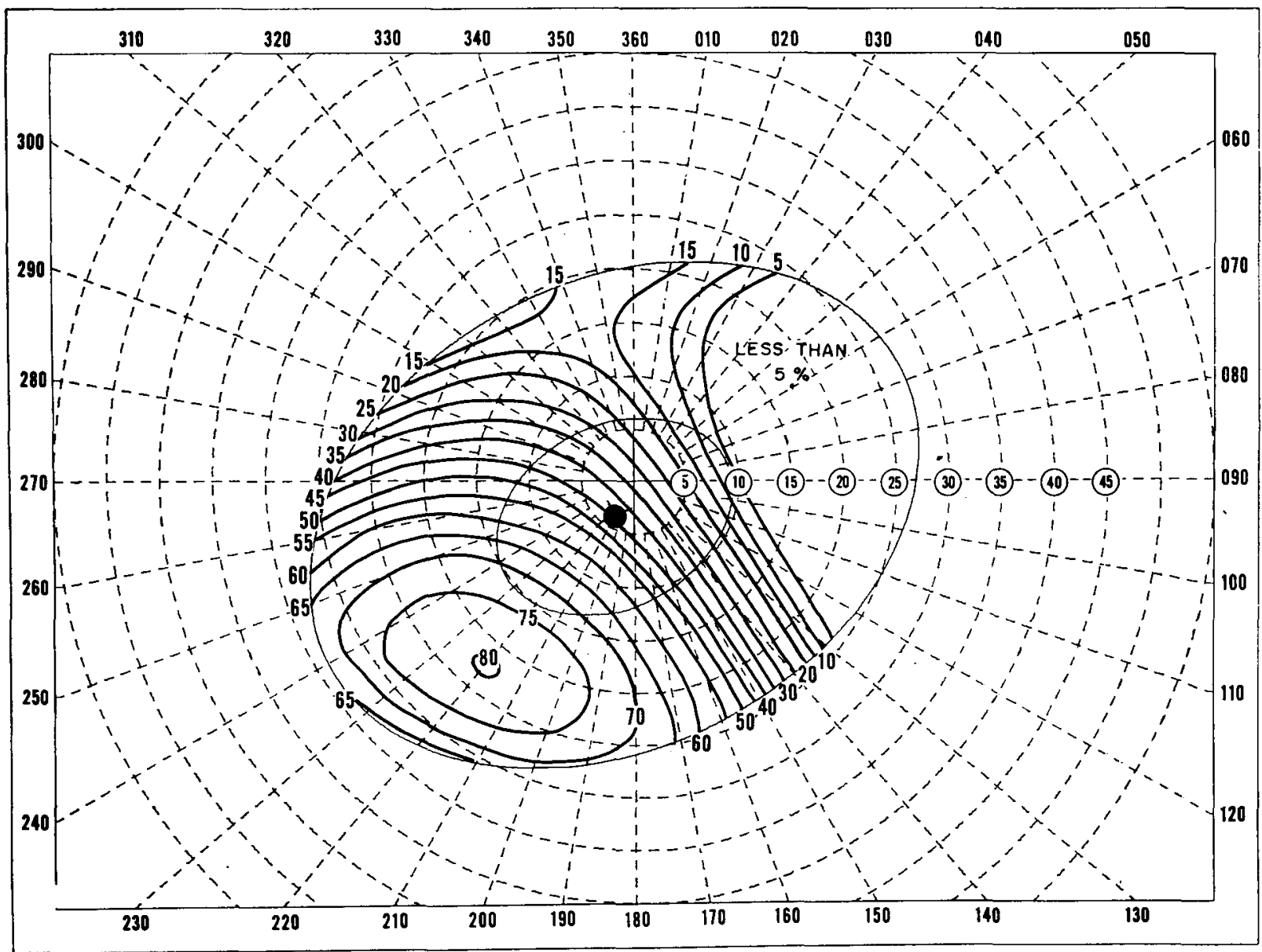

FIG. 13. Probability of afternoon thunderstorms in the month of June as a bivariate function of the 850-mb 1200 GMT wind speed (kt, circled) from specified directions (degrees). Outer and inner ellipses encompass 99 and $50 \%$ of the dependent-data sample; the darkened circle is the centroid of the sample. 


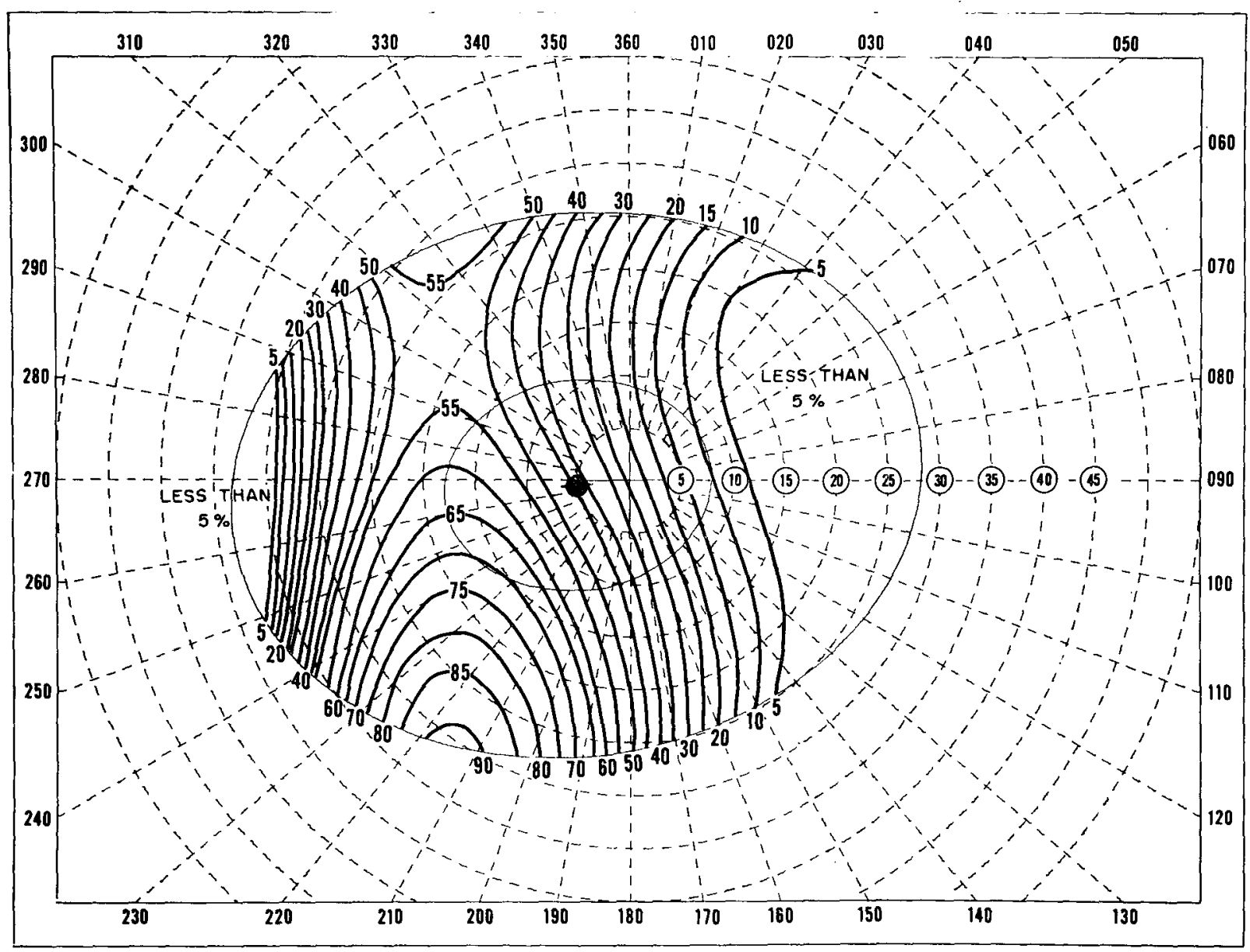

FIG. 14. Same as Fig. 13 except for the $500-\mathrm{mb}$ wind speed.

of an ellipse in the $(s, t)$ coordinate system, i.e.,

$$
\begin{aligned}
\phi_{99}(s, t)= & {[(s-h) \cos \theta+(t-k) \sin \theta]^{2} /\left(3.035 s^{\prime}\right)^{2} } \\
& +[(t-k) \cos \theta-(s-h) \sin \theta]^{2} /\left(3.035 t^{\prime}\right)^{2},
\end{aligned}
$$

where $\theta$ is the angle of rotation of the major axis of the ellipse from the positive $s$ axis, $h$ and $k$ are the centroids (mean $s$ and mean $t$ ) of the ellipse, and $s^{\prime}$ and $t^{\prime}$ are the standard deviations of the $s$ and $t$ components along the major and minor axes, respectively. Values of $s^{\prime}, t^{\prime}$ and $\theta$ are obtained by fitting the array of all $s$ and $t$ components to a bivariate normal distribution. Details of this fitting process are given in Hope and Neumann (1970). The constant 3.035 in the denominators of the right side of (13) represents a particular choice of probability such that $99 \%$ of the dependent-data observations should be included in the resultant ellipse. Substituting appropriate values in (13) gives the bounding function

$$
\begin{aligned}
\phi_{99}(s, t)=0.00128 s^{2}+ & 0.00189 t^{2}-0.00084 s t \\
& +0.0021 s+0.0107 t+0.020 .
\end{aligned}
$$

The outer ellipse in Fig. 13 represents the locus of all $s$ and $t$ values obtained by setting (14) to unity. The regression program output illustrated in Fig. 12 prints a warning message whenever (14) exceeds unity. The inner ellipses in Figs. 13 and 14 are presented for information only and encompass $50 \%$ of the cases.

It is obvious from Figs. 13 and 14 that the relationship between thunderstorm occurrence and the winds is definitely not a linear one. At both the 850- and 500$\mathrm{mb}$ levels, southwesterly winds are highly favorable. Speed, though, is also an important factor. In Fig. 15, it can be seen that the effect of mean relative humidity is also quite noniinear. Here, it is not the humidity itself that contributes to thunderstorm occurrence but rather a third factor, synoptic-scale vertical motion, that controls both humidity and thunderstorm potential. Low humidities are indicative of subsidence which suppresses afternoon convection. High humidities at this time of the morning (0700 EST) are indicative of considerable synoptic-scale convergence and excessive cloudiness which do not allow sufficient afternoon convection. Mean relative humidities in the range $60-80 \%$ are an optimum value between the two extremes just cited. 


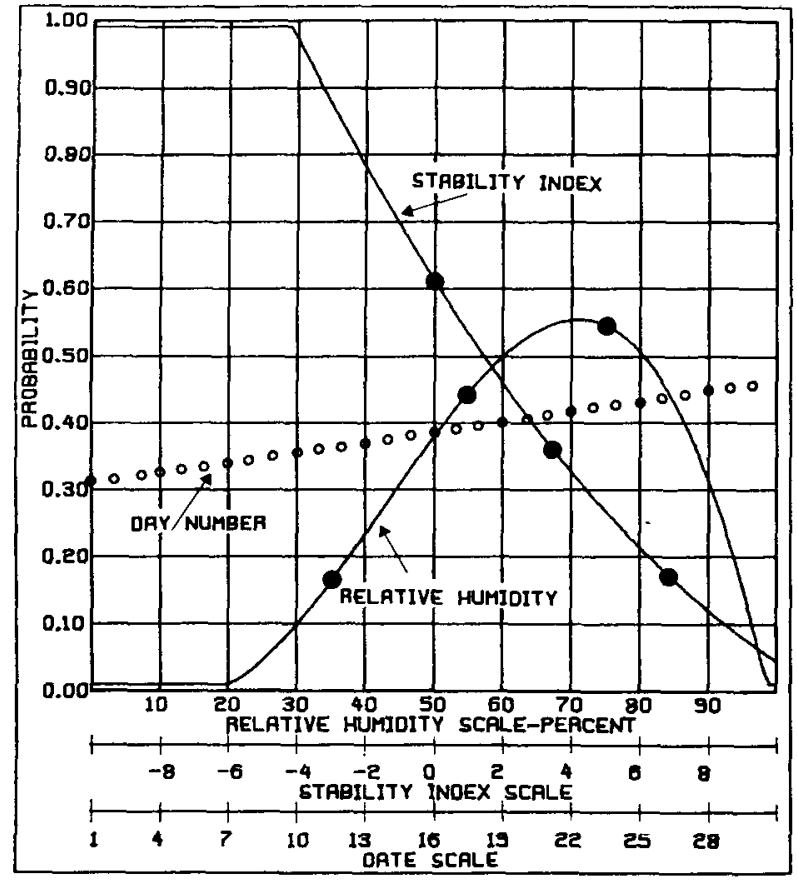

Frg. 15. Probability of afternoon thunderstorms as univariate functions of stability index, mean $800-600$-mb relative humidity, and date for the month of June. Darkened circles show locations of mean and plus or minus one standard deviation.
Note that the humidity and the stability index curves in Fig. 15 are discontinuous at $P=0.99$ and $P=0.01$. These values are beyond the range of the dependent-data sample and were assigned using $a$ priori reasoning.

Solutions to each of the five functions (8)-(12) are given in the program output illustrated in Fig. 12. In this way, the forecaster is made aware of the contributions of each of the predictor functions to the final combined probability. For the month of June on any given date, one would expect maximum thunderstorm probability to occur with an $850-\mathrm{mb}$ wind of from $220^{\circ}$ at $22 \mathrm{kt}$, a $500-\mathrm{mb}$ wind from $214^{\circ}$ at $30 \mathrm{kt}$, a mean humidity of $71 \%$, and a low stability index.

\section{c. Thunderstorm slarting time}

The computer output shown on Fig. 12 also includes an estimate of thunderstorm starting time (TST). A separate regression equation was formulated to provide this information. The starting times were shown to be a function of four predictors

$$
\mathrm{TST}=f(s, t, P, D),
$$

where $s$ and $t$ are the orthogonal wind components at $850 \mathrm{mb}, P$ the forecast thunderstorm probability, and $D$ the current day number. Most of the reduction in

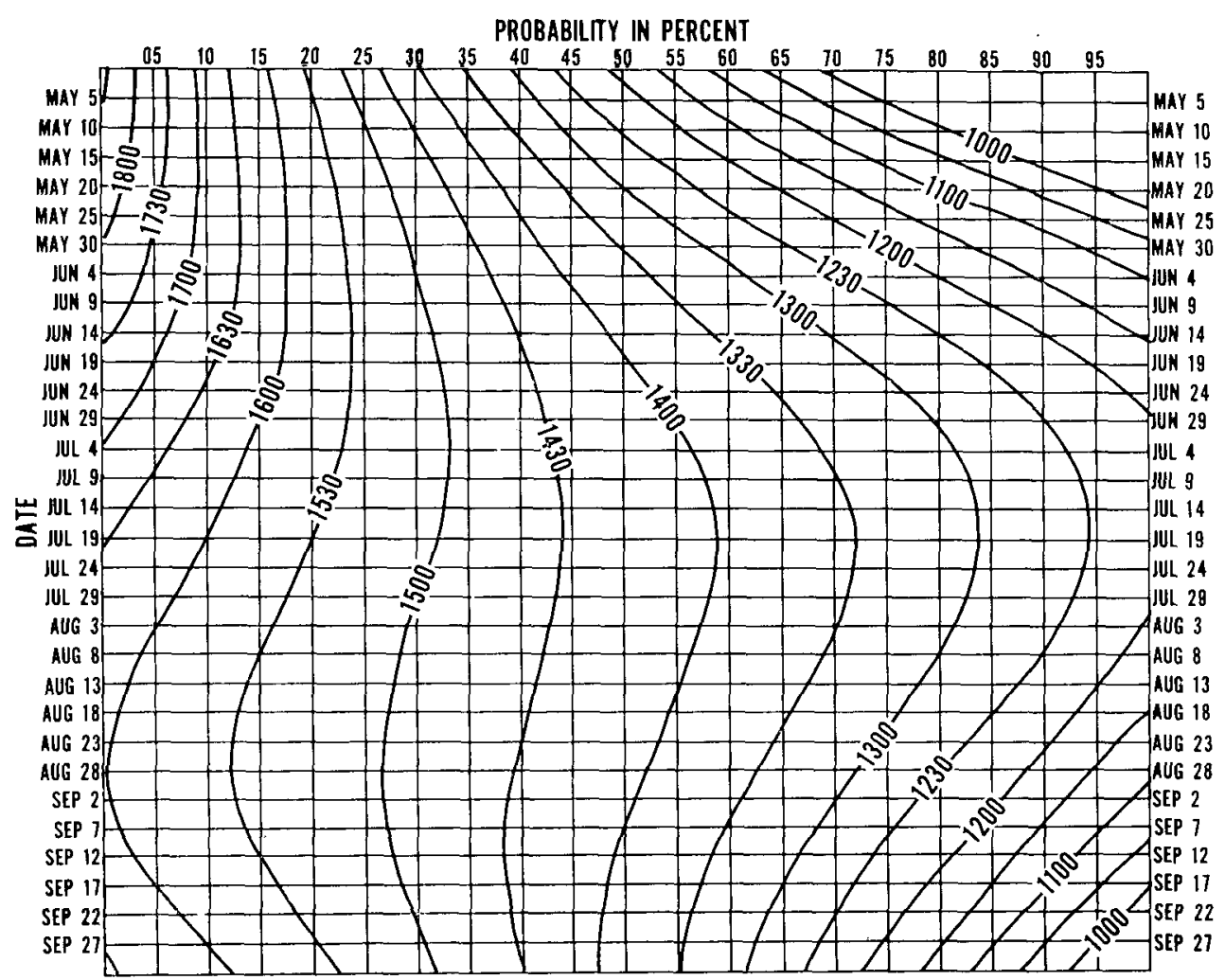

FIG. 16. Most probable thunderstorm starting time as a function of calm $850-\mathrm{mb}$ winds and specified forecast probability and date. 


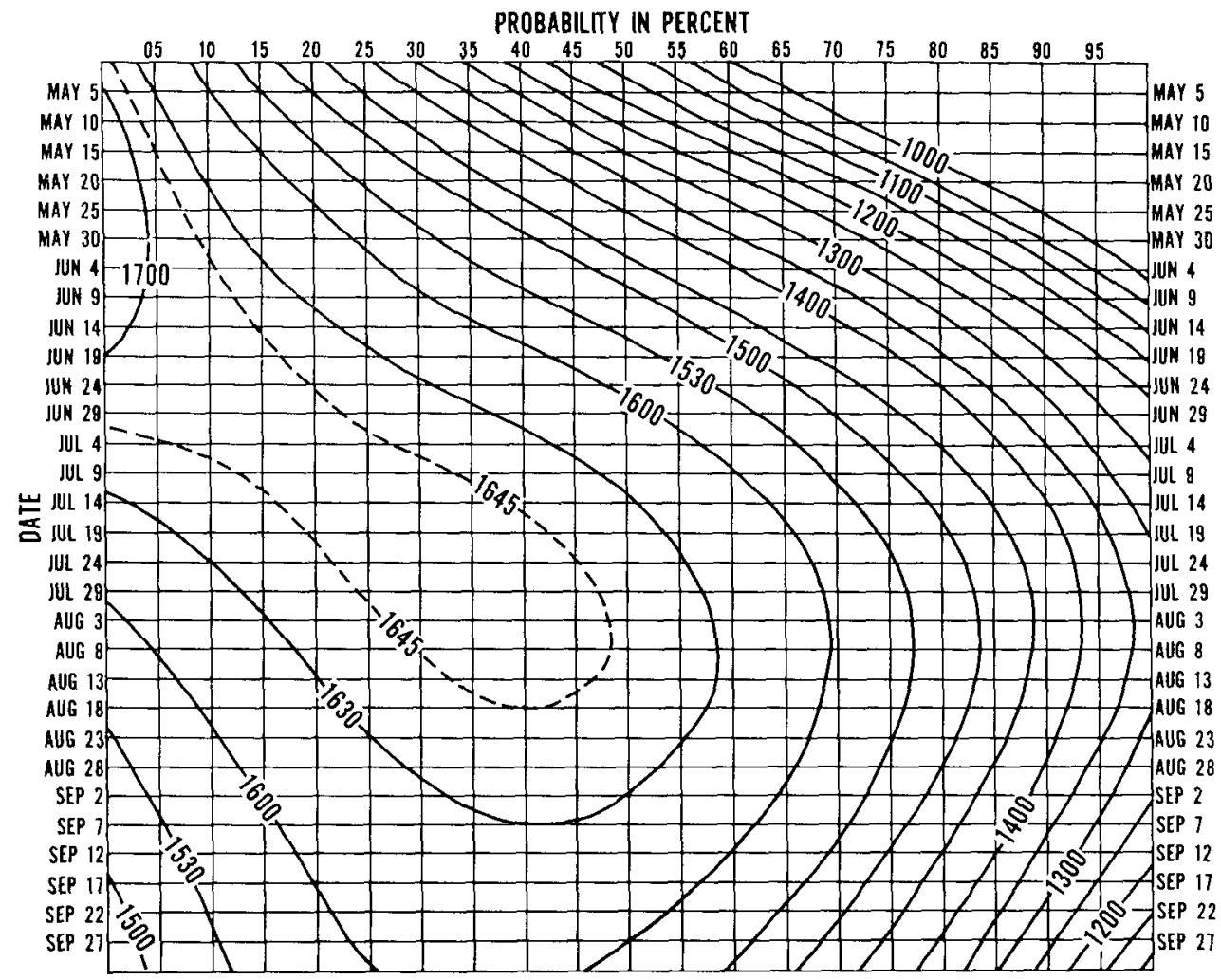

FIG. 17. Most probable thunderstorm starting time as a function of an $850-\mathrm{mb}$ wind $\left(180^{\circ}\right.$ at $\left.10 \mathrm{kt}\right)$ and specified forecast probability and date.

variance is provided by the forecast probability. By holding two of the four independent variables in (15) constant, TST can be represented graphically in a two-dimensional space. Figs. 16 and 17 present two such solutions for selected values of $s$ and $t$. The 850$\mathrm{mb}$ wind $\left(180^{\circ}, 10 \mathrm{kt}\right)$ used in Fig. 17 was selected to represent the sample input data used to arrive at Fig. 12. The probable error associated with (15) is plus or minus $1 \frac{1}{2} \mathrm{hr}$.

\section{Extreme short-range forecasts}

Once a thunderstorm system is in progress within a reasonable distance from the Space Center, the forecaster must speculate as to its temporal and spatial disposition. Although data from an elaborate observational network (Amman, 1970) convey the current status, the forecaster is still called upon to extrapolate trends into the future. Techniques are being developed to provide objective assistance.

During the 1970 thunderstorm season, 225 individual thunderstorm cells that came within a reasonable distance of the launch facilities were tracked by radar. Positions of the leading edge of the most intense return were noted at approximate 10 -min intervals. These positions and other information about the cell were then transferred to magnetic tape for further evaluation. This tracking program will be continued in sub- sequent seasons. Using techniques analogous to those developed by Hope and Neumann (1968) and Neumann (1969), for hurricane track forecasts, it is planned to arrive at probability forecasts of a given cell being within a given distance of a given site at a given time. Other approaches are also being investigated. Goldman (1970), for example, uses an elaborate mesoscale wind system to test a dynamic-empirical model of thunderstorm outflow.

\section{Discussion}

It has been demonstrated that thunderstorm data can be processed in a variety of ways, each designed to present specific answers to specific forecast requirements. Using conditional probabilities, the forecaster is alerted as to how nature has reacted to a given set of circumstances over the period of record. It should be stressed here that the final decision is up to the forecaster. The various objective tools presented herein are merely steps in what might be called the forecaster's decision ladder (Simpson, 1971). It is hoped that some of these techniques may be adaptable to thunderstorm forecasting elsewhere.

The system of regression equations derived in Section 7 is not claimed to be the most effective possible, nor is it claimed that additional predictors will not reduce the variance further. It may be possible, for example, 
to arrive at a single set of prediction equations for the entire thunderstorm season rather than using time steps of one month as was done herein. Discontinuities from one month to the next would thereby be avoided. Work is continuing to increase the effectiveness of the system.

Acknowledgments. The author is indebted to his colleagues at the Spaceflight Meteorology Group at the Kennedy Space Center and at Miami for their assistance and encouragement during the course of these studies. The cooperation and foresight of Mr. Irving Kuehnast of the Air Weather Service, Detachment 11, and other personnel associated with the Air Force Eastern Test Range in obtaining the radar tracking data is also greatly appreciated. Statistical guidance on some phases of the study was provided by Mr. John Hope of the National Hurricane Center.

\section{REFERENCES}

Amman, E. A., 1970: Lightning and static electricity considerations at the Kennedy Space Center. Proc. Lightning and Static Electricity Conf., San Diego, Calif., Soc. Automotive Engineers.

Brooks, C. E. P., and N. Carruthers, 1953: Handbook of Statistical Methods in Meteorology. London, Meteor. Office Publ. No. 538, p. 332.

Byers, H. R., and H. R. Rodebush, 1958: Causes of thunderstorms of the Florida peninsula. $J$. Meteor., 15, 275-280.

Ezekial, M., 1941: Methods of Correlation Analysis. New York, Wiley, $347 \mathrm{pp}$.

Falls, L. W., W. O. Williford and M. C. Carter, 1971: Probability distributions for thunderstorm activity at Cape Kennedy, Florida. J. Appl. Meteor., 10, 97-104.

Frank, N. L., P. L. Moore and G. E. Fisher, 1967 : Summer shower distribution over the Florida Peninsula as deduced from digitized radar data. $J$. A ppl. Meteor., 6, 309-316.

Goldman, J. L., 1970: The bottom 500 feet of thunderstorm associated winds. Preprints of Papers, Fourth Natl. Conf. Aerospace Meteorology, Las Vegas, Nev., Amer. Meteor. Soc. and Amer. Inst. Aeronautics Astronautics, 233-238.

Hope, J. R., and C. J. Neumann, 1968: Probability of tropical cyclone induced winds at Cape Kennedy. ESSA Tech. Memo. WBTM SOS-1, $67 \mathrm{pp}$.

_- and - - 1970: An operational technique for relating the movement of existing tropical cyclones to past tracks. Mon. Wea. Rev., 98, 925-933.

Landsberg, H., 1958: Pliysical Climatology, 2nd ed. DuBois, Pa., Gray, 257 pp.

Lass, H., 1957: Elements of Pure and Applied Mathematics. New York, McGraw-Hill, 345 pp.

Mills, F. C., 1955: Statistical Methods, 3rd ed. New York, Holt, Rinehart and Winston, pp. 147, 612-656, 601, 727-731.

Neumann, C. J., 1968: Frequency and duration of thunderstorms at Cape Kennedy, Part 1. ESSA Tech. Memo. WBTM SOS-2, 34 pp.

_- 1969: Probability of tropical cyclone induced winds at NASA Manned Spacecraft Center. ESSA Tech. Memo. WBTM SOS-4, $46 \mathrm{pp}$.

- 1970: Frequency and duration of thunderstorms at Cape Kennedy, Part 2. ESSA Tech. Memo. WBTM SOS-6, $63 \mathrm{pp}$.

_- 1971: Thunderstorm forecasting at Cape Kennedy, Florida, utilizing multiple regression techniques. ESSA Tech. Memo WBTM SOS-8, (in press).

_ and J. R. Hope, 1971: A performance analysis of the HURRAN tropical cyclone forecast system (submitted for publication).

Simpson, R. H., 1971: The decision procession in hurricane forecasting. NOAA Tech. Memo., NWS SR-53, National Weather Service, $35 \mathrm{pp}$.

Smith, O. E., L. W. Falls and S. C. Brown, 1967: A statistical analysis of winds for aerospace vehicle design, mission planning, and operations. NASA Tech. Memo. NASA TM X-53706, Marshall Space Flight Center, Huntsville, Ala., p. 24. 